\title{
LA EMPRESA SOCIALMENTE RESPONSABLE: Una propuesta de autoevaluación
}

\author{
Nissim Alcabés \\ UNIVERSIDAD ESAN (PERÚ) \\ nalcabes@esan.edu.pe
}

\section{Resumen}

El autor propone que las empresas se autoevalúen respecto al grado en que su desempeño, frente a su personal, a la sociedad y al país, refleja uno socialmente responsable. Para ello sugiere diez variables susceptibles de autoevaluación y una final que sintetiza las anteriores. También señala, citando al profesor Sumantra Ghoshal, la necesidad de revisar conceptos teóricos que en cierta medida han deshumanizado la conducción de las empresas.

Palabras clave: responsabilidad social, autoevaluación, teoría de la empresa.

\begin{abstract}
The author proposes that corporations should self-evaluate the degree to which their performance towards their personnel, society and the nation is rated as socially responsible. He suggests 10 self-evaluation variables and a final overarching criterion. Quoting professor Sumantra Ghoshal, the author points to the need to review theoretical concepts that may have somehow dehumanized corporate management.
\end{abstract}

Key words: social responsibility, self-evaluation, corporate theory.

$\mathbf{E}$ Perú, al igual que muchos otros países en este mundo globalizado, ha adoptado los paradigmas del mercado de libre competencia que rigen las economías de los países desarrollados, con todas sus bondades y, simultáneamente, con algunas innegables consecuencias negativas. Sin embargo, no todos los impactos adversos pueden atribuirse exclusivamente al «modelo». La normatividad estatal y la «conducta» de las empresas, los empresarios y los altos directivos juegan un papel y tienen qué decir al respecto. Por esto hoy está en boga el concepto de «respon- sabilidad social de la empresa», muchas veces entendida como acciones emprendidas por una empresa determinada en beneficio de ciertos grupos sociales o poblacionales, especialmente en relación con las comunidades del entorno de sus principales operaciones.

Mejor sería referirse a la «empresa socialmente responsable», aquella conducida de modo que denota visible consideración por aspectos que interesan a la comunidad donde opera y a los miembros de la propia empresa. 
Tratándose de las acciones de empresas cotizadas en las bolsas de valores se presume que dicho precio condensa toda la información que sobre estas empresas disponen los agentes económicos participantes en el mercado bursátil. ¿Incluye tal precio la apreciación acerca del desempeño socialmente responsable de las empresas cotizadas? La respuesta es no, aunque sí existen entidades que toman en cuenta tales apreciaciones respecto de cierto número de empresas. Estas calificaciones no aparecen en los listados que diariamente se publican de las cotizaciones bursátiles y tampoco influyen en tales cotizaciones.

\section{Planteamientos conceptuales}

Es casi un lugar común decir que la dirección o gerencia de una empresa tiene como principal objetivo «maximizar el valor de la misma para sus accionistas o propietarios». Fue Milton Friedman, premio Nobel de Economía, quien en su libro Capitalism and freedom expresara:

Ha ido ganando amplia aceptación la opinión de que los funcionarios corporativos y los líderes sindicales tienen «una responsabilidad social» que va más allá de servir los intereses de sus accionistas o de sus miembros. Este punto de vista muestra un error fundamental del carácter y naturaleza de los negocios - usar sus recursos y comprometerse en actividades diseñadas para incrementar sus utilidades mientras se mantenga dentro de las reglas del juego, lo que quiere decir, empeñarse en competencia abierta y libre, sin engaño o fraude-. [...] Pocas tendencias pueden tan completamente socavar los fundamentos de nuestra sociedad libre como la aceptación por los funcionarios corporativos de una responsabilidad social distinta de la de hacer tanto dinero para sus accionistas como sea posible. Esta es una doctrina fundamentalmente subversiva ${ }^{1}$.

El planteamiento de Friedman tiene amplia aceptación tanto en la teoría económica como en la teoría de la gerencia de empresas, especialmente en la teoría financiera. Lástima que no explicitó esas «reglas del juego» dentro de las cuales deben mantenerse los directivos empresariales $-\mathrm{o}$ no recibieron siquiera la mínima difusión que requerían-.

Sin embargo, distinguidos autores discrepan radicalmente de la posición de Friedman. Así, Sumantra Ghoshal expresa:

Las teorías de la gerencia en el presente son abrumadoramente causales o funcionales en sus modos de explicación. Ética o moral, sin embargo, son fenómenos mentales. Como consecuencia, ellas han tenido que ser excluidas de nuestra teoría y de las prácticas que tales teorías han moldeado [...]. Cuando gerentes, incluyendo los máximos ejecutivos (CEO) justifican sus acciones alegando su impotencia ante las fuerzas externas, recurren a la deshumanización de la práctica que emplean ${ }^{2}$.

1. Milton Friedman, with the assistance of Rose D. Friedman. Capitalism and freedom. Chicago: The University of Chicago Press, 1962, pág. 133. La obra reúne conferencias dictadas por el autor en junio de 1956. (Traducción propia).

2. Sumantra Ghoshal. Bad management theories are destroying good management practices. Academy of Management Learning \& Education. Vol. 4, n. ${ }^{\circ}$ 1, Mar. 2005, pág. 79. (Traducción propia). El autor fue profesor de la London Business School. Este artículo fue el último que escribió antes de fallecer, a principios del 2004. En la misma edición aparecen siete artículos comentándolo, escritos por reconocidos académicos. 
Luego Ghoshal añade:

También sabemos que el valor que una compañía crea es producido mediante la combinación de los recursos aportados por diferentes grupos. Los empleados, incluyendo los gerentes, contribuyen con su capital humano, por ejemplo, mientras que los accionistas contribuyen con capital financiero. Si la creación de valor es lograda por la combinación de los recursos de ambos, los empleados y los accionistas, ¿por qué la distribución de valor favorece únicamente a los últimos? ¿Por qué debe la corriente principal de nuestra teoría estar fundamentada en la maximización de los beneficios para justamente uno de estos varios contribuyentes? [...]. La respuesta -la única respuesta que es realmente válida- es que este supuesto ayuda en la estructuración y solución de elegantes modelos matemáticos ${ }^{3}$.

Vemos, pues, que el «dictum» de Milton Friedman, en el sentido de que la función de la gerencia es maximizar las utilidades o el valor de la empresa para sus accionistas, no es plenamente aceptado y, más bien, van ganando terreno quienes discrepan radicalmente con su posición y propugnan una visión más humana de la conducción y fines de la empresa.

\section{Cómo determinar el desempeño socialmente responsable: la autoevaluación}

El valor de la empresa se incrementa a medida que genera «utilidades» derivadas de sus operaciones. La utilidad de la empresa es igual a sus ingresos totales menos sus costos totales, esto es Ut $=\mathrm{I}-\mathrm{C}$.

3. Ghoshal, Op cit., pág. 80. (Traducción propia).
Entre los costos se encuentran el costo del personal de todas las áreas: gerencia, administración, distribución y mercadeo; el costo de las materias primas e insumos utilizados; el costo de servicios adquiridos de terceros; los impuestos y otras contribuciones pagadas; los intereses pagados; los costos en los que se incurre en las actividades de investigación y desarrollo; y otros.

Dado que en un mercado de libre competencia no puede ponerse límites a priori a la maximización de las utilidades y, por ende, al incremento del valor de la empresa, la única manera de saber si la firma es «socialmente responsable» es determinar si tiene en consideración y cumple con atender debidamente a los otros integrantes o interesados en la misma: sus trabajadores en todos los niveles, los clientes a quienes dirige sus productos y servicios, sus proveedores, la comunidad donde opera y otros stakeholders (titulares de interés en el desempeño de la empresa).

Para facilitar la respuesta, es deseable que sea la propia empresa la que efectúe autoevaluaciones anuales de su desempeño como entidad socialmente responsable, cuyo resultado le servirá para mejorar su propio desempeño. Mejor aun, debe divulgar dichos resultados sometiéndose al juicio de la sociedad. Sin duda, las empresas que denoten mejores niveles de desempeño socialmente responsable, percibidos del mismo modo por la sociedad, se verían favorecidas por esta.

¿Cómo efectuar la autoevaluación?, ¿qué aspectos de la actividad empresarial pueden ser relevantes para este fin? A continuación sugiero diez variables o dimensiones por medio de las cuales las 
empresas podrán examinar su desempeño a fin de establecer cuán socialmente responsables son.

1) Estructura de los egresos por remuneraciones. Las personas que trabajan en una organización u empresa constituyen lo esencial de la misma. Son todos seres humanos, todos creación divina, todos iguales en la consideración y el respeto que se les debe a su dignidad. Son quienes aportan sus energías, creatividad y lealtad para el logro de los objetivos de la empresa.

Se suele definir la organización como la agrupación de «personas» con fines comunes o con un conjunto de fines comunes. La consideración que los propietarios y altos directivos de una empresa tengan por su personal es, por tanto, sumamente importante. Tal consideración se refleja de diversas maneras, pero, sin duda, se cristaliza en el nivel de remuneración que percibe cada trabajador -desde la posición de menor jerarquía hasta la más encumbrada-. En el primer caso, la remuneración debe permitir por lo menos una vida digna, aunque sea modesta. Para examinar cuán responsable es en este aspecto, la empresa debiera elaborar, anualmente, un cuadro de la participación de los diversos niveles de su personal en el total de remuneraciones y compensaciones que abona, dividiendo al personal en cinco quintiles, de menor a mayor remuneración (remuneración total, que incluya todo rubro percibido o que signifique beneficios individuales, incluyendo acciones u opciones para adquirirlas). Luego determinará el número de personas incluido en cada quintil y lo multiplicará por el promedio de las remuneraciones incluidas en ese quintil. Así podrá establecer qué proporción del egreso total de la empresa por este rubro es percibido por quienes integran el quintil superior y compararlo con la proporción que recibe el quintil inferior. Se completará la información comparando los promedios de las remuneraciones pagadas en cada quintil con el valor de la canasta familiar. Así podrá encontrarse fácilmente si las remuneraciones del quintil más bajo cubren el valor de la canasta familiar o sólo una fracción de ella.

En las estadísticas nacionales suele publicarse la proporción del ingreso que percibe el quintil o el decil de más altos ingresos de la población comparada con la cifra correspondiente a los sectores de más bajos ingresos. Se trata, pues, de precisar lo que sucede al interior de las empresas.

Debe tenerse presente que mientras mayor sea el número de trabajadores bien remunerados, más alta será su capacidad adquisitiva y, en consecuencia, se impulsará el movimiento económico del país. En la medida en que las empresas ofrezcan bienes y servicios de calidad y competitivos, es de esperar que una alta proporción de esa mayor capacidad adquisitiva se destine a los producidos en el país.

2) Generación o disminución del empleo. Un aspecto muy importante del desempeño social de una empresa es determinar si genera empleo o, más bien, lo disminuye, como suele suceder cuando se realizan fusiones o adquisiciones «para mejorar la eficacia y eficiencia de la organización», en resumidas cuentas, para elevar su rentabilidad. Cuando suceden tales fusiones o adquisiciones realmente no se está creando: sólo se cambia de propietarios y se consolidan operaciones. No se realizan nuevas inversiones o se crean nuevas 
empresas que signifiquen creación de empleo. Para los fines de este indicador, la empresa (o grupo empresarial) indicará el número total de sus trabajadores, de todos los niveles jerárquicos, al inicio del ejercicio, más el total de personas contratadas durante el mismo, menos el total de personas que dejaron de laborar en la empresa (ideal sería que se distinga entre los retiros voluntarios y los ceses), para así llegar al personal total al finalizar el ejercicio.

\section{3) Preservación del medio ambiente. En} las últimas décadas, la preocupación por la preservación del medio ambiente y el desarrollo autosostenible -que no implique la dilapidación de los recursos naturales- ha adquirido dimensión internacional y es materia tanto de acuerdos multilaterales como de investigaciones sobre las consecuencias dañinas que puedan generarse. Baste referirse al calentamiento global. Mucho es lo que una empresa puede hacer al respecto, aun en ausencia de legislación nacional apropiada, sin exponerse a perder posición competitiva. Para determinar cuán responsable es en este aspecto, la empresa se autocalificará en una escala de 1 a 5 , indicativa de menor a mayor preocupación efectiva por la calidad del ambiente en el desarrollo de sus operaciones. Tendrá que establecer el grado en que contamina la atmósfera, las aguas y la tierra como consecuencia de sus procesos productivos o la disposición de sus desperdicios, y la magnitud del riesgo al que pueden quedar expuestas las poblaciones en sus áreas de acción.

\section{4) Preocupación por la salud ocupacio-} nal de su personal. Igualmente, mediante autocalificación en la escala sugerida, la empresa mostrará su preocupación por la salud de su personal. Tomará en cuenta el número de casos de enfermedades ocupacionales diagnosticadas en el periodo y el número de accidentes de trabajo atribuibles a insuficiencia de los medios de prevención o protección -sin perjuicio de indicar los accidentes producidos por negligencia de los propios trabajadores-. También cabe considerar el estrés laboral, producto de una elevada tensión emocional a causa de factores como el temor a la pérdida del empleo y el surgimiento de problemas familiares debido a los horarios de trabajo muy extendidos.

En este aspecto, al igual que en el caso anterior, la empresa puede hacer visible su preocupación por la salud de su personal sin necesidad de esperar legislación nacional apropiada u obligaciones contractuales con el Estado, si se trata de concesiones. Cierto que no se puede ignorar las limitaciones que impone el cuidar la posición competitiva, pero lo que haga y divulgue la empresa sobre su acción puede contribuir a que tal legislación se dicte y sea obligatoria para todos los competidores en el mismo ramo, lo que anularía cualquier desventaja relativa.

5) Grado de satisfacción de los clientes con los productos o servicios de la empresa. Para examinar cuán responsable es en este aspecto, la empresa aplicará la escala sugerida para los casos anteriores. Sin duda, el mejor indicador será el grado de aceptación de sus productos y servicios, tal como se transparenta por el nivel de sus ventas y la evolución de las mismas a lo largo del tiempo. La apreciación de esta dimensión se vinculará a la que se indica a continuación, pues es distinta la situación cuando los competidores son numerosos que cuando el mercado es relativamente oligopólico. 
6) Intensidad de la competencia. Esta dimensión se estimará subjetivamente, aplicando la escala de 1 a 5 . No hará falta precisar cifras ni mencionar competidores específicos. De esto podrían ocuparse los analistas, si fuere necesario. Se trata de exteriorizar el contexto de las operaciones de la empresa, si presenta numerosos competidores o unos pocos.

7) Aprovechamiento de los recursos naturales del país o de insumos nacionales. $\mathrm{Al}$ indicar el porcentaje que representan el valor de los insumos naturales del país o los insumos nacionales sobre el total de los empleados en todos sus procesos, la empresa está obteniendo un indicador de cuánto contribuye a la generación de empleo en el país y al ahorro de divisas, obviamente cuando la producción nacional sea competitiva y de la calidad requerida. No se pretende que deba existir alguna forma de protección a las empresas nacionales, pero sí es fundamental que se fortalezca permanentemente el ambiente para que las empresas se esfuercen por elevar sus estándares de competitividad, tanto respecto a sus rivales nacionales cuanto a los internacionales. La globalización ocasiona que cualquier empresa situada en las antípodas devenga en un competidor importante para una empresa orientada exclusivamente al mercado nacional.

\section{8) Proporción de las exportaciones sobre} el valor de la producción total de la empresa. Considerando que las exportaciones contribuyen al desarrollo del país y a la creación de empleo, así como al aprovechamiento de los recursos naturales y de los insumos nacionales, al informar sobre este indicador -sea año a año o con promedios por periodos multianualesla empresa permitirá una mejor interpretación de las autoevaluaciones sugeridas, especialmente en el párrafo anterior.
9) Utilidades del ejercicio como porcentaje del patrimonio accionario o de los propietarios invertido en el país. Al dedicar por lo menos una parte de sus utilidades a inversiones en el Perú, la empresa hace evidente su compromiso con el desarrollo nacional. No se pretende disminuir la importancia en la diversificación mediante inversiones en otros países, pues estas son en cierta medida una contraparte a las inversiones extranjeras en el Perú. Un porcentaje muy bajo denotará lazos poco firmes. Al reinvertir en el país, la empresa estará contribuyendo a la generación de nuevos empleos y al desarrollo de la economía nacional. El índice puede referirse al ejercicio o al promedio en un periodo de tres a cinco años, ya que el ritmo de reinversión no tiene por qué ser semejante cada año.

10) Contribución de la empresa a obras o acciones en beneficio de comunidades nacionales. La empresa puede autoevaluarse indicando en la escala de 1 a 5 cómo se percibe con relación a sus acciones directas o aportes a programas $\mathrm{u}$ obras en beneficio de comunidades en el país. Mejor aun sería si indica el porcentaje promedio de sus utilidades asignadas a tales acciones en un periodo de tres o cinco años. Sería la expresión cuantitativa de su «responsabilidad social».

Finalmente, como resumen del examen de las diez dimensiones descritas, y con base en las calificaciones anteriores, la empresa puede obtener la evaluación global de su comportamiento socialmente responsable, expresado en la escala de 1 a 5; es decir, una apreciación general de cuán socialmente responsable se considera desde el punto de vista de sus propios altos directivos. 
La serie de indicadores planteados son, sin duda, susceptibles de refinamiento. $\mathrm{Su}$ aplicación será la mejor guía para ello.

\section{Conclusión}

La función gerencial, especialmente de la alta gerencia, implica enfrentarse a demandas opuestas, como maximizar utilidades per se frente a consideración por los aspectos humanos y sociales; satisfacer objetivos de corto plazo frente a los de largo plazo; delegar autoridad decisoria en instancias inferiores de la estructura gerencial o centralizarla en los altos niveles. Tal polaridad significa que los gerentes deben constantemente tratar de equilibrar las demandas extremas, como ya lo señalaba Peter Drucker. No hay recetas ni fórmulas para resolverlas, sino el criterio ilustrado de quienes tienen a su cargo la conducción de las organizaciones, para lo cual deben prepararse y cultivarse a lo largo de la vida.

En cuanto al tema central de esta propuesta, si bien en lustros recientes las es- cuelas de administración de negocios han puesto énfasis en el dictado de cursos de ética y responsabilidad social, cabe preguntarse si ello es suficiente o si, como lo sugiere el artículo de Sumantra Ghoshal, es necesario revisar algunas teorías hoy por hoy consideradas fundamentales en la formación y desempeño de los gerentes.

La ética -que se puede resumir en la regla de oro de «respetar al prójimo»-se aprende en el hogar, desde los primeros años de vida y se refuerza durante la escolaridad. En la universidad más que «aprender» ética, corresponde analizar y estudiar su aplicación a la infinidad de situaciones que presenta la vida real. Pero en estos análisis aplicativos, las teorías que aceptamos para guiar el desempeño profesional-gerencial-son críticas.

Creo, al igual que muy distinguidos académicos, y por los argumentos expuestos, en la necesidad de revisar tales teorías y humanizarlas. 